\title{
EFFECT OF FLUORIDE IONTOPHORESIS APPLICATION ON MICRO- LEAKAGE OF LOW SHRINKAGE RESIN COMPOSITES
}

\author{
Wakwak MA*, Mohamed T.M. Fayed ${ }^{* *}$, Belal.S.A. Ali ${ }^{* *}$ and Nady I.M. Hassanein ${ }^{* * *}$
}

\begin{abstract}
The present study was directed to evaluate the effect of fluoride Iontophoresis application on microleakage of low shrinkage resin composites. Materials and Methods; A total of 180 freshly extracted human non carious premolar teeth were used. Three (C- factor) (60 teeth each), half of the teeth received fluoride Iontophoresis application (FI), while the other half were not received any treatment (NF). Teeth were restored with Silorane resin composite and Kalore resin composite. The specimens stored for one month, three months and six months in distilled water at $37^{\circ} \mathrm{C}$ in an incubator. After storage time and sealing procedures and dye immersion in silver nitrate $50 \%$ wt. for 12 hours. The tooth restoration interface and investigated under Scanning Electron Microscope (SEM). Result; The results of this study revealed that less microleakage of Silorane than kalore. There was significant difference between flat tooth surface and both of classII and classV. Lower leakage score for the fluoridated Silorane and kalore restorations than none fluoridated one at all C-factors and at three and six storage times. Conclusions; Fluoride iontophoresis have a better effect on microleakage. C-factor significantly affected on the marginal seal.
\end{abstract}

\section{INTRODUCTION}

One of the major drawbacks is polymerization shrinkage, which consequently leads to the generation of polymerization stress that may causing debonding between tooth structure and resin composite that reduce the longevity of the restoration ${ }^{(1,2)}$. Silorane resin composite type of monomer is obtained from the reaction of oxirane and siloxane molecules, the silorane composite polymerizes by a cationic process, which is insensitive to oxygen in contrast to methacrylate ${ }^{(3,4)}$. Also, the Dupont Kalore has a unique property of DX511 monomer consists of a long rigid core with flexible side arms and a lower number of double bonds make it low shrinkable composite. Among the adverse clinical consequences of the polymerization shrinkage, failure at the compositecavity interface and microleakage ${ }^{(5)}$. Microleakage is one of the most frequent problems associated with resin composites, Polymerization stresses are generated within the restoration and at the margins, and if these stresses exceed the bond strength microleakage may occur at the tooth restoration interface ${ }^{(6-8)}$. Cavity configuration factor (C-factor) is the ratio of the bonded surface area in a cavity to the unbonded surface area ${ }^{(9,10)}$. The increase in $\mathrm{C}$-factor is associated with progressive weakening of the bond strength ${ }^{(11,12)}$.

Fluoride ion is one of the most important anticaries agents ${ }^{(13,14)}$. The concentration of fluoride ions in dentinal tubules increased due to the fluoride iontophoresis. But, the application of fluoride may adversely affect the bond strength of some dentin bonding systems ${ }^{(15)}$. So, fluoride therapy could influence the marginal microleakage of composite resin restorations.

\footnotetext{
* Lecturer of Operative Dentistry, Faculty of Dental Medicine, Al-Azhar University (Cairo-Boys).

** Professor of Operative Dentistry Department, Faculty of Dental Medicine, Al-Azhar University, Cairo(Boys). *** Assistant Professor of Operative Dentistry, Faculty of Dental Medicine, Al-Azhar University, Cairo (Boys).
} 


\section{Materials \& Methods: Materials;}

TABLE (1) Resin composite and their adhesive:

\begin{tabular}{|c|c|c|c|}
\hline Product name & Category & Composition & $\begin{array}{l}\text { Manufacturer and } \\
\text { Batch number }\end{array}$ \\
\hline $\begin{array}{l}\text { Filtek (P90) } \\
\text { Silorane shade } \\
\text { A3 }\end{array}$ & $\begin{array}{l}\text { Low shrinkable } \\
\text { restorative } \\
\text { micro-hybrid } \\
\text { resin composite }\end{array}$ & $\begin{array}{c}\text { 5-15\%3,4epoxycyclohexylethylcyclo-polymethylsiloxane;5- } \\
\text { 15\%bis-3,4-epoxy-cyclohexylethylphenylmethylsila } \\
\text { ne;50-70\% silanizedquartz;10-20\%yttrium-fluoride; } \\
\text { camphorquinone }\end{array}$ & $\begin{array}{c}\text { 3M ESPE Dental Product } \\
\text { St. Paul, MN, USA } \\
\text { (3MESPE, website } \\
\text { www.3mespe.com) } \\
(468933)\end{array}$ \\
\hline \multirow[t]{2}{*}{$\begin{array}{l}\text { Silorane } \\
\text { adhesive } \\
\text { System } \\
\text { (two steps) }\end{array}$} & self-etch primer & $\begin{array}{l}\text { 15-25\% 2-hydroxyethyl methacrylate (HEMA) }{ }^{*}, 15-25 \% \\
\text { bisphenol a diglyceryl ether methacrylate (BIS-GMA) }{ }^{* *} \text {, } \\
1015 \% \text { water, 10-15\% ethanol, 5-15\% phosphoric acid- } \\
\text { methacryloxy hexylesters, } 8-12 \% \text { silane treated silica, } 5-10 \% \\
\text { 1,6-hexanediol dimethacrylate, , 3\% camphorquinone and 3\% } \\
\text { phosphine oxide }\end{array}$ & $\begin{array}{c}\text { 3M ESPE Dental Product } \\
\text { St. Paul, MN,USA } \\
(466373) \\
\text { (3MESPE,website } \\
\text { www.3mespe.com) }\end{array}$ \\
\hline & $\begin{array}{l}\text { Adhesive - } \\
\text { Bond }\end{array}$ & $\begin{array}{l}\text { 70-80\% substituted dimethacrylate, } 5-10 \% \text { silane } \\
\text { treated silica, 5-10\% triethylene glycol dimethacrylate } \\
(\text { TEGDMA) })^{* * *} \text {, phosphoric acid methacryloxy-hexylesters, }\end{array}$ & $\begin{array}{l}\text { 3M ESPE Dental Product } \\
\text { St. Paul, MN,USA } \\
\text { (456311)(3MESPE,website } \\
\text { www.3mespe.com) }\end{array}$ \\
\hline $\begin{array}{c}\text { Kalore } \\
\text { ShadeA3 }\end{array}$ & $\begin{array}{l}\text { nano-hybrid } \\
\text { composite }\end{array}$ & $\begin{array}{c}\text { Urethane dimethacrylate(UDMA) }{ }^{+} 18 \%, \text { DX-511 co- } \\
\text { monomer Dimethacrylate,Fillers(Fluoroaluminosilicate } \\
\text { glass), Prepolymerized filler , Silicon dioxide, photo initiator, } \\
\text { Pigment }\end{array}$ & $\begin{array}{c}\text { GC, Tokyo Japan } \\
\qquad(1010091) \\
\text { website www.gc-dental.com }\end{array}$ \\
\hline $\begin{array}{l}\text { G-aenial } \\
\text { (One step) }\end{array}$ & $\begin{array}{l}\text { self etch } \\
\text { adhesive }\end{array}$ & $\begin{array}{l}\text { 4-Methacryloxyethyltrimllitate anhydride } 5-10 \% \text {, acetone } 30 \text { - } \\
40 \% \text {, water } 15-20 \% \text {, Dimethacrylat } 15-20 \% \text {, phosphoric acid } \\
\text { ester monomer } 15-20 \% \text {, silicon dioxide } 1-5 \% \text {, photoinitiator }\end{array}$ & $\begin{array}{c}\text { GC, Tokyo Japan } \\
\text { (12101121) } \\
\text { Website www.gc-dental.com }\end{array}$ \\
\hline
\end{tabular}

"HEMA: 2-hydroxyethyl-methacrylate. ${ }^{* *}$ BIS-GMA: bisphenol-a-diglycidyl-ether-dimethacrylate.

****TEGDMA: tri-ethylene-glycol-dimethacrylate. +UDMA: Urethane dimethacrylate.

Fluoride iontophoresis device (Jonofluor, Medical, Via Olivera, Italy) and its Fluoride gel (Fig. 1);

This device consists of; A plastic tray with metal plate in the fitting surface of the try extended above the handle and a disposable grooved sponge adapted in the try that act as a carrier for the fluoride gel. Two electrodes; the positive anode and the negative cathode. $1.23 \%$ acidulated phosphate fluoride (APF) gel (12 300 p.p.m. F, pH 3.5). Milliampere (mA) monitor display range from $(0.2 \mathrm{~mA}, 0.4 \mathrm{~mA})$. Battery charge for current supply and switch on / off.

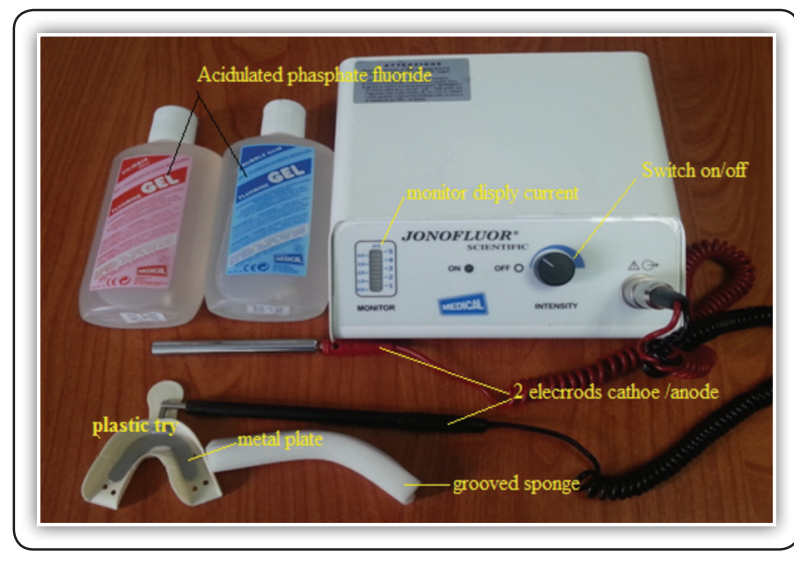

FIG (1) Iontophoresis device. 


\section{Methods;}

A total of 180 freshly extracted non carious intact human premolar teeth without any cracks or fractures and any developmental anomalies were collected from the maxillofacial clinic at the Faculty of Dentistry, Al-Azhar University and were stored in glass jars with distilled water at room temprature until the experimental time. $\mathrm{C} 1$ factor $(\mathrm{C} 1)$; (one bonded surface) A standardized flat tooth surface was prepared in 60 teeth (30 for Silorane group and 30 for Kalore group) using carbide burs ${ }^{1}$ in high-speed handpiece with profuse water-coolant. C3 factor (C3); (3 bonded surfaces) A standardized Class II MOD cavity without any axial step prepared in 60 teeth by using carbide burs ${ }^{2}$ in high-speed handpiece with profuse water-coolant. Bucco-lingual width occlusally $(2 \mathrm{~mm})$ in the middle $1 / 3$ rd of the cusp tip of the teeth. The cavity depth was $2 \mathrm{~mm}$. C5 factor (C5); (5 bonded surface) Standardized class $\mathrm{V}$ cavities were prepared on buccal surface of 60 teeth. The dimensions of class $\mathrm{V}$ cavities were $2 \mathrm{~mm}$ mesio-distally, $2 \mathrm{~mm}$ depth and $2 \mathrm{~mm}$ occlusogingivally with the gingival margin at least $1.0 \mathrm{~mm}$ above the CEJ. The preparation was done by using carbide burs $^{3}$ in high-speed handpiece with profuse water-coolant

After cavity preparation iontophoresis was done for 30 prepared teeth from each C-factor with $1.23 \%$ acidulated phosphate fluoride (APF) gel according to manufacturer's instructions, and electrically charged with $0.4 \mathrm{~mA}, 12 \mathrm{~V}$ for $4 \mathrm{~min}$, while the other 30 prepared teeth from each $\mathrm{C}$-factor were not receive any fluoride treatment $(\mathrm{NF})$

\section{Application of resin composite;}

According to the manufacturer's instructions, application of adhesive system and the restorative material of all groups was applied by incremental

1. \#245SC carbide burs, Brasseler, Savannah, GA, USA.

2. \#703 carbide burs, Brasseler, Savannah, GA, USA.

3. \#257, SS White, Great White Series, Lakewood, NJ, USA. technique and light cured for $40 \mathrm{sec}$. After restorative procedures the teeth were stored in water at $37^{\circ} \mathrm{C}$ in an incubator with $100 \%$ humidity at different storage time (one month, three months and six months) until they were tested. The specimens were immersed in an aqueous solution of $50 \mathrm{wt} \%$ ammoniacal silver nitrate $(\mathrm{pH} 9.5)$ for $24 \mathrm{~h}$, followed by $8 \mathrm{~h}$ in a photo-developing solution. Teeth were sectioned longitudinally.

The degree of dye penetration was assessed by using a modified scoring system according to the following criteria (figure2);

Score $0=$ No dye penetration

Score $\mathrm{I}=$ Dye penetration along enamel wall only.

Score $2=$ Dye penetration along enamel and extend up to1 $\mathrm{mm}$ in dentinal wall.

Score 3= Dye penetration along enamel and extend $2 \mathrm{~mm}$ in dentinal wall for flat tooth surface and for class II, while extend along the entire length of the cervical floor of class $\mathrm{V}$.

Score $4=$ Dye penetration up to the dentin bridge more than $2 \mathrm{~mm}$ in dentinal wall for flat dentin and classII, while extend along the entire length of the cervical floor and one-half of the axial wall of classV.

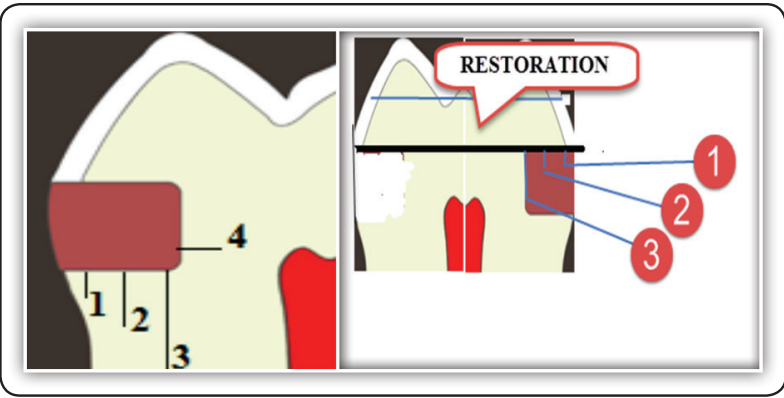

FIG (2) Diagram represinting the score of microleakage. 


\section{RESULTS}

The mean leakage score and standard deviation values of the collected data were calculated for each group. Statistical analysis for the mean of each group were done using Kruskal-Wallis test followed by Mann-Whitney $U$ test to compare between the different variables. The significance level was set at $(\mathrm{P} \leq 0.05)$. Statistical analysis was performed with software IBM ${ }^{\circledR}$ SPSS ${ }^{\circledR}$ Statistics version 20 .

For flat tooth surface $(\mathrm{C} 1)$; the mean leakage score value of fluoridated specimens $(0.98 \pm 0.07)$ was higher than the mean leakage score of nonfluoridated specimens $(0.88 \pm 0.06)$ with significant difference between them where $\mathrm{p}$-value $=(0.04)$. For class II (C3); the mean leakage score value of non fluoridated specimens $(1.85 \pm 0.3)$ was higher than the mean leakage score of fluoridated specimens $(1.64 \pm 0.05)$ with significant difference between them where $\mathrm{p}$-value $=(0.03)$. For class $\mathrm{V}$ (C5); the mean leakage score value of non fluoridated specimens $(2.10 \pm 0.7)$ was higher than the mean leakage score of fluoridated specimens $(1.86 \pm 0.08)$ with significant difference between them where p-value $=(0.03)$.

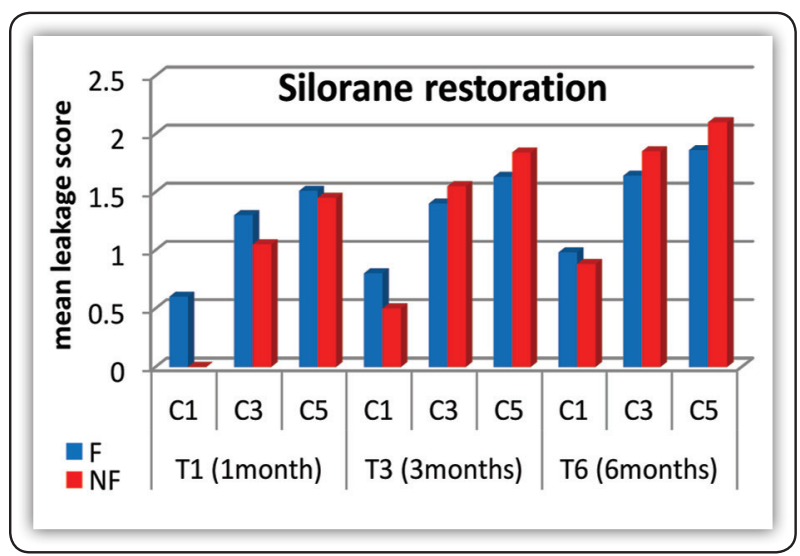

FIG (3) Bar chart representing the comparison between fluoridated and non fluoridated specimens within each Cfactor at different storage times of Silorane restoration.

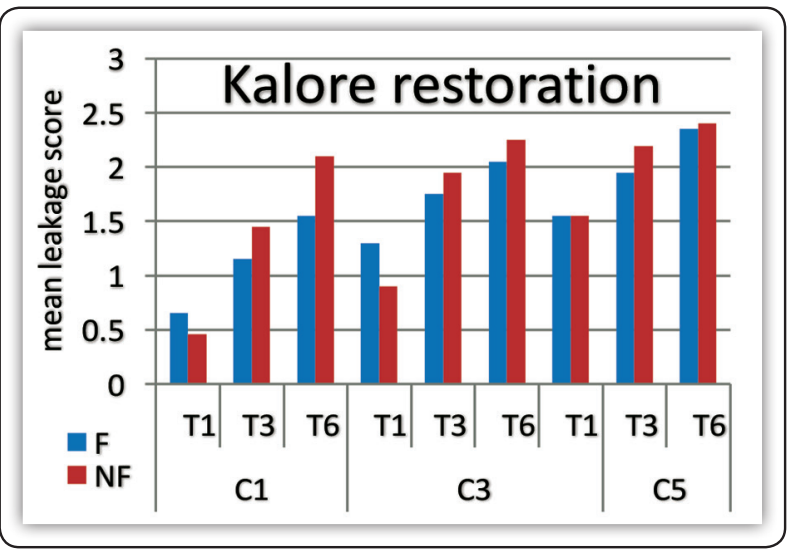

FIG (4) Bar chart representing the comparison between fluoridated and non fluoridated specimens within each Cfactor at different storage times of Kalore restoration.

\section{Scanning Electron Microscope observations:}

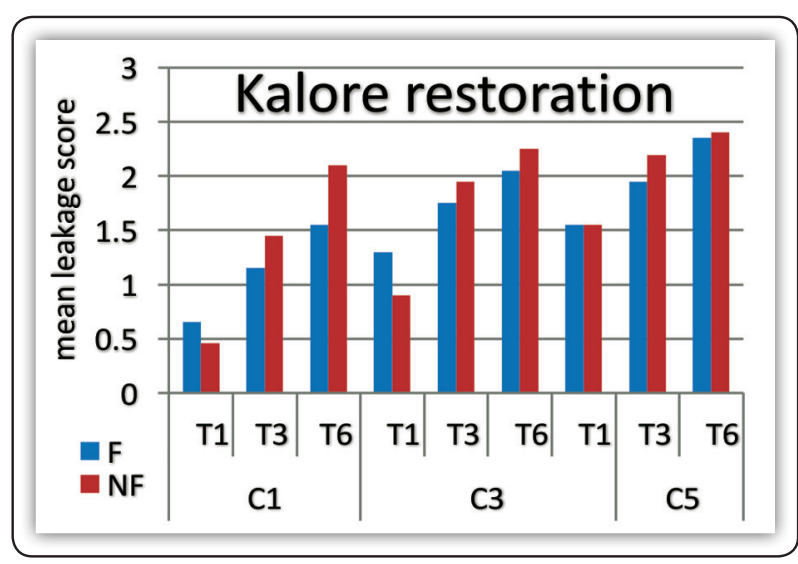

FIG (5) Scanning Electron Microscope (SEM) was used to determine the marginal gap.

\section{DISCUSSION}

In the current study, lower microleakage scores obtained with Silorane could also be attributed to the ring opening chemistry of the Silorane system and the use of different nature of the Silorane system adhesive ${ }^{(16)}$. Silorane based composite resin possess two key advantages: polymerization shrinkage lower than $1 \%$ due to the presence of oxirane monomers and increased hydrophobicity due to the presence of siloxane in its composition $(3,4)$. On the other hand, the Kalore with its adhesive (one step self etch adhesive) showed amount of 
microleakage more than silorane, this could be due to the acidity of one step adhesive that contain large portion of hydrophilic component which interfere with the efficiency of polymerization of adhesive monomer ${ }^{(17)}$. Incomplete hydrophobic sealing of G-aenial bond with Kalore cause the incomplete polymerized hydrophilic resin component that may be elute from adhesive and hybrid layer in the short term ${ }^{(18)}$, unlikeness to Silorane adhesive which contains a very hydrophobic bond with separate self etching primer that convert the wet hydrophilic collagenous surface to a dry hydrophobic surface. This hydrophobic nature of the Silorane adhesive is manifested as a lack of water diffusion, which could exhibit little microleakage ${ }^{(19,20)}$.

The result of this study is in agreement with the results of Thalaker et al ${ }^{(21)}$, that confirm better marginal integrity in the silorane fillings initially after placing and after exposure to mechanical stress. Also, is in agreement with the result of Yamazaki et al ${ }^{(22)}$, which stated that the Silorane resin composite showed reduced polymerization shrinkage and stress, as well as significantly improved marginal adaptation compared with methacrylate resin composite. Asmussen and Peutzfeldt (23) also, reported that the Silorane-based resin composite had significantly lower polymerization contraction than the other resin-based composites. This would appear to indicate that ring opening has taken place with a concomitant contraction that is relatively small $^{(24)}$.

The results of this study that showed leakage in Silorane and Kalore resin composite was disagree with the result of Bagis et al ${ }^{(25)}$, that revealed the silorane-based resin composite had no microleakage for wide MOD restorations with oblique and vertical layering techniques. Also, Schmidt et al ${ }^{(26)}$, revealed that there were no statistically significant differences in microleakage between Silorane and other resin composites. This controversy could be due to the difference in methodology and nature of their study.
Fluoridated and non-fluoridated groups, revealed lower leakage score for the fluoridated Silorane and kalore restorations than non-fluoridated one at all Cfactors and at three and six storage times. While at one month storage, fluoridated Silorane and Kalore specimens had higher leakage score than non fluoridated groups.

This may be attributed to that fluoride ions chemically react with calcium ions in dentin to form calcium fluoride and with hydroxyapatite crystals to form fluorapatite that occluded partially or completely dentinal tubules. Even a small reduction in tubule diameter after fluoride iontophoresis will significantly decrease fluid conductance in the tubules ${ }^{(15)}$. The formation of acid-resistant fluoride reaction products at the dentin surface and in the tubule, orifices could be occurred and effect on the bond strength ${ }^{(27)}$.

Self-etching bonding systems of Silorane and Kalore, etch (condition) and prime dentin simultaneously without the need for rinsing. They partially dissolve the smear layer and hydroxyapatite crystals to yield a superficial resin-infiltrated zone with minerals incorporated ${ }^{(28,29)}$. The self-etching system is less aggressive, which demineralizes dentin and consequently forms more and deeper resin tags, usually achieving higher bonding strengths ${ }^{(30)}$.

On the other hand, the higher leakage score of fluoridated Silorane and Kalore groups after one month storage, may attributed to fluoride iontophoresis that mainly decrease the effectiveness of dentin adhesives by reducing the deeper infiltration of resin monomers into the pretreated fluoridated specimens, the same as for the effects of acid-resistant calcium oxalate crystals resulted from application of potassium oxalate that may occlude the dentinal tubules ${ }^{(31)}$.

The results of fluoride application are in agreement with Shabzendedar et al ${ }^{(32)}$, that revealed low microleakage in the group that received acidulated phosphate fluoride (APF) before 
composite resin placement than the control group. Another result showed pre-treatment with fluoride could not affect the marginal leakage ${ }^{(33)}$. Also, Giannopoulos et al ${ }^{(34)}$, was showed that treatment with APF before bonding results in on significant change in composite bond retention.

Furthermore, the result of this study counteracts the study with Kecskemet et al ${ }^{(35)}$, that found more microleakage in fluorosis teeth than nonfluorosis teeth and microleakage levels increased depending on the severity of dental fluorosis. These higher microleakage levels may be explained by a weaker bonding of composite restorations on fluorosed teeth because of the pitted and detachable fluoroapatite structure of fluorosed enamel which has hypermineralized surface layer and quite extensive subsurface porosity ${ }^{(36)}$.

\section{CONCLUSIONS}

1. The marginal seal was significantly better in cavities with lower $\mathrm{C}$-factor than in cavities with higher $\mathrm{C}$-factor.

2. Fluoride iontophoresis treatment increased significantly the leakage value.

3. Long term storage in water dramatically increased microleakage.

4. Cavity adaptation of a low-shrinkage Silorane based resin composite was comparable to that of Kalore resin composite.

\section{REFERENCES}

1. Ferracane JL. Developing a more complete understanding of stresses produced in dental composites during polymerization. Dent Mater 2005; 21:36-42.

2. Bouillaguet S, Gamba J, Forchelet J, Krejci I, Wataha JC. Dynamics of composite polymerization mediates the development of cuspal strain. Dent Mater J 2006; 22:896-902.

3. Weinmann W, Thalacker C, Guggenberger R. Siloranes in dental composites. Dent Mater 2005; 21:68-74.

4. Ilie N, Jelen E, Hickel R. Low shrinkage composite for dental application. Dent Mater 2007; 26: 149-155.
5. Tanno K, Hiraishi N, Otsuki M, Tagami J. Evaluation of cavity adaptation of low-shrinkage composite resin. Asian Pac J Dent 2011; 11: 27-33.

6. Gwinnett JA, Tay FR, Pang KM, Wei SH. Comparison of three methods of critical evaluation of microleakage along restorative interfaces. J Prosthet Dent.1995; 74:575-85.

7. Palin WM, Fleming GJ, Burke FJ, Marquis PM, Randall RC. The influence of short and medium-term water immersion on the hydrolytic stability of novel low-shrink dental composites. Dent Mater 2005; 21:852-63.

8. Boroujeni P, Mousavinasab S, Hasanli E. Effect of configuration factor on gap formation in hybrid composite resin, low-shrinkage composite resin and resin-modified glass ionomer. J Invest Clin Dent 2015; 6: 156-60.

9. Van Ende A, De Munck J, Mine A, Lambrechts P, Van Meerbeek B. Does a low-shrinking composite induce less stress at the adhesive interface? Dent Mater 2010; 26:215-22.

10. Feilzer AJ, De Gee AJ, Davidson CL. Setting stress in composite resin in relation to configuration of the restoration. J Dent Res 1987; 66:1636-9.

11. Nikolaenko SA, Lohbauer U, Roggendorf M. Influence of c-factor and layering technique on microtensile bond strength to dentin. Dent Mater 2004; 20:579-85.

12. Ghulman MA. Effect of cavity configuration (C-factor) on the marginal adaptation of low-shrinking composite: a comparative ex vivo study. Inter J Dent 2011; 8: 17-24.

13. Surender S, Rajan G, Gaurav G. Iontophoresis and Dentistry. JIDA 2011; 5:46-48.

14. Mahbobeh S, Horieh M, Fatemeh K, Avideh DM. The effect of topical fluoride therapy on microleakage of tooth colored restorations. J Conserv Dent. 2011; 14(3): 297-301.

15. Chen LJ, Meng QF, Chen YM, Smales RJ, Yip KH. Effect of fluoride iontophoresis on the microtensile bond strength between dentin and two adhesive systems. J Dent 2008; 36(9): 697-702.

16. Van Ende A, Mine A, De Munck J, Poitevin A, Van Meerbeek B. Bonding of low-shrinking composites in high C-factor cavities. J Dent. 2012; 40:295-303.

17. Takahashi H, Finger WJ, Wegner K, Utterodt A, Komatsu M, Wostmann B, et al. Factors influencing marginal cavity adaptation of nanofiller containing resin composite restorations. Dent Mater 2010; 26: 1166-75.

18. Hahnel S, Henrich A, Burgers R, Handel G, Rosentritt M. Investigation of mechanical properties of modern dental composites after artificial aging for one year. Oper Dent 2010; 35:412-9. 
19. Hegde MN, Vyapaka P, Shetty S. A comparative evaluation of microleakage of three different newer direct composite resins using a self-etching primer in class $\mathrm{V}$ cavities: An in vitro study. J Conserv Dent. 2009; 12:160-6.

20. Papadogiannis D, Kakaboura A, Palaghias G, Eliades G. Setting characteristics and cavity adaptation of low-shrinking resin composites. Dent Mater 2009; 25: 1509-16.

21. Thalacker C, Heumann A, Hampe R, Weinmann W, Guggenbeeger R, Syrek A. Marginal integrity of silorane and methacrylate restorations after load cycling. J Dent Res 2005. Abstr. No. 0277 Available from: http://iadr.confex. com/ iadr/2005Balt/techprogram/abstract_62667.

22. Yamazaki PC, Bedran-Russo AK, Pereira PN. Microleakage evaluation of a new low-shrinkage composite restorative material. Oper Dent2006; 31:670-6.

23. Asmussen E and Peutzfeldt A. Polymerization contraction of a silorane-based resin composite and four methacrylate based composites. Euro Cells Mater 2005; 10:8-12.

24. Boaro LC, Goncalves F, Guimaraes TC, Ferracane JL, Versluis A, Braga RR. Polymerization stress, shrinkage and elastic modulus of current low-shrinkage restorative composites. Dent Mater 2010; 26: 1144-50.

25. Bagis YH, Baltacioglu IH, Kahyaogullari S. Comparing microleakage and the layering methods of silorane-based resin composite in wide Class II MOD cavities. Oper Dent 2009; 34:578-85.

26. Schmidt M, Kirkevang LL, Horsted BP, Poulsen S. Marginal adaptation of a low-shrinkage silorane-based composite: 1-year randomized clinical trial. Clin Oral Investig 2011; 15:291-5.

27. Huang GF, Guo MK. Changes of dentinal tubules following fluoride Iontophoresis. NSCC 1995;19: 246-52.
28. Kungel G, Ferrari M. The science of bonding: from first to sixth generation. J Amer Dent Assoc 2000; 131:20-5.

29. Tabari M, Esmaeili B, Alimohammadi M, Poorsattar Bejeh Mir A, Gharekhani S, Hajiahmadi M, et al. Comparative evaluation of microleakage of composite restorations using fifth and seventh generations of adhesive systems. Caspian J Dent Res 2014; 3: 14-9.

30. Jhingan P, Sachdev V, Sandhu M, Sharma K. Shear bond strength of self-etching adhesives to cavities prepared by diamond bur or ER,CR:YSGG laser and effect of prior acid etching. J Adhes Dent 2015; 17:505-12.

31. Tay F, Pashley D, Mak Y, Carvelho R, Lai S, Suh B. Integrating oxalate desensitizers with total-etch two-step adhesive. J Dent Rese 2003; 82:703-7.

32. Shabzendedar $\underline{\mathrm{M}}, \underline{\text { Moosavi H}}, \underline{\text { Kebriaee F, Daneshvar A }}$ The effect of topical fluoride therapy on microleakage of tooth colored restorations. J Conserv Dent. 2011; 14:297301.

33. Nystrom GP, Holtan JR, Olin PS, Douglas WH. Technical note: fluoride pre-treatment effects on microleakage of a resin bonding agent. Dent Mater. 1989; 5:359-60.

34. Dionysopoulos P, Gerasimou P, Tolidis K. The effect of home-use fluoride gels on glass-ionomer, compomer and composite resin restorations. J Oral Rehabil 2003; 30:683-9.

35. Kucukeşmen C, Sonmez H. Microleakage of class V composite restorations with different bonding systems on fluorosed teeth. Eur J Dent 2008;2: 48-58.

36. Ateyah N, Akpata E. Factors affecting shear bond strength of composite resin to fluorosed human enamel. Oper Dent 2000; 25:216-22. 
